\title{
Population Development in Finland - A Challenge for Society! ${ }^{1}$
}

\author{
MAURI NIEMINEN
}

\author{
Senior Adviser \\ Population Statistics \\ Statistics Finland, Helsinki
}

\begin{abstract}
The most significant factor shaping the Finnish age pyramid has been fertility. After World War II fertility took an unprecedented climb. When fertility was at its highest in 1947, the total fertility rate was 3.46. After this fertility began to drop year by year.

Because of the large proportion of the population composed by those of working age, Finland has had a favorable age structure compared to that of other countries. Finland's working-age population has been one of the highest in the world. But in the future this favorable age structure will change and the proportion of aging population will increase rapidly. In 2030 almost every third person will be over 65 years old in Finland.
\end{abstract}

Keywords: population, fertility, mortality, migration, population projections, Finland

The size and the structure of the population are important in regard to the development of society. In Finland we are now living at a time when population growth has been one of the lowest in the world for the last two decades. The size of the population and its age structure are significant when examining economic and social development. In the industrialized countries, the actual size of the population has no significance for development. Instead, the age structure of the population both now and in the years to come is the factor on which interest will increasingly be focused.

\section{The decline in the birth rate}

The biggest factor shaping the Finnish age pyramid has been the birth rate. The birth rate began to decline right after the First World War. Each year the new age group being born was smaller than its predecessor, until the birth rate began to rise again in the mid-1930s. After the unsettled years of the Second World War, the birth rate took

${ }^{1}$ This paper is a condensation of an article which appeared in TTT Katsaus, Vol. 20, No. 4, 1992, a journal published by the Labour institute for Economic Research. 
Fig u re 1: The age structure of the population in 1990 and 2030

1990

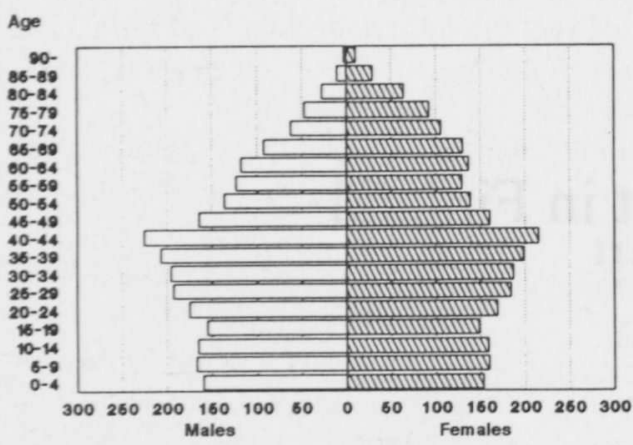

2030

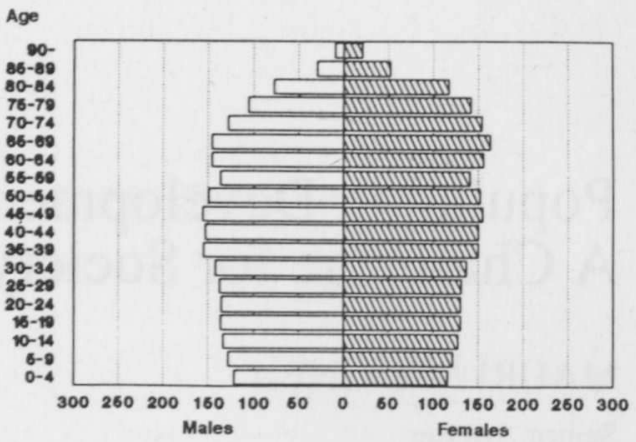

Source: Statistics Finland, population projection.

an unprecedented climb. In 1947 a record number of children were born, over 108,000. After this the birth rate began to drop year by year and the number of births was continuously smaller than that of the previous year (Figure 1).

In 1973 the smallest age group since independence was born, 57,000 children. After that the birth rate rose slightly and, with a few exceptions, has remained at almost the same level.

When fertility was at its highest in 1947, right after World War II, the total fertility rate was 3.46 . The fertility rate was at its lowest in 1973 at 1.50 . Fertility then reached close to 1.70 , where it has remained, with the exception of the last few years. In 1991 the total fertility rate was 1.81 .

The decline in the birth rate after World War II was one of the most rapid in the industrialized world of the west. However, the starting point right after the war was high. The reasons for the drop in the birth rate can be found mainly in the changes brought about by economic and social development.

After the war Finland experienced a truly rapid change in its industrial structure. This transition could be seen in the rise of migration from the rural areas to the urban areas. Labor force was released from agriculture, and engaged by industry. While almost one-half of the gainfully employed population still made its living in agriculture in 1950 , by 1970 this proportion had dropped to one-third and is now already under 10 percent.

The decline in the birth rate has taken place concurrently with economic growth. The same has occurred in many other countries. Various benefits - child benefits, tax concessions - have not brought about an increase in the birth rate. They may lead temporarily to a small rise in the birth rate, but their long-term effect is minimal.

On the other hand, people's attitudes and values are important when examining how the birth rate has developed over the last few decades. The emphasis has often been primarily on material values, and thus many families have decided to keep their family small.

The birth rate is lower among the more educated than among the less educated, it is also lower among urban dwellers than among those living in rural areas, and the more extended education of women has decreased the birth rate. Especially in Finland, where the employment of women has increased over the last few decades so that it is now the highest in the western world, this has had an impact on the level of the birth rate. At the end of the 1960s, Finns began to take part in the increased use of contraceptives promoting family planning. This provided families with entirely new 
possibilities for regulating the size of their family and has had a significant effect on the birth rate.

On the basis of research data on the family and fertility gathered by Statistics Finland in 1989 (Nikander 1992), it can be noted that the factors decreasing fertility had already prevailed for several decades. Almost 5,000 women who were born in 19381967 were interviewed for the study.

In all the birth cohorts, the results supported the reasons presented above for the decrease in fertility. In all the cohorts the more highly educated had had fewer children than those with less education. Compared by educational level, the more highly educated had an average of 1.6 children, while among those with only a basic education the number of children rose to 2.4 .

In addition, fertility was higher among the agricultural population than among the rest of the population. While the average number of children among those earning their living in agriculture was almost three, managers and senior administrative and clerical employees had an average of only two children.

The last age group to renew itself were the women born in 1939-40. Their average number of children exceeds the 2.1 children needed for renewal. Starting with the next age group, women have no longer given birth to the number of children required for population renewal. Thus the gain in population from the birth rate has slowed down year by year.

\section{The decline in mortality}

A male Finnish child born today will live an average of 71 years and a female child 79 years. At the international level, the expected lifespan of women stands up to comparison, but the life expectancy of men is one of the lowest in the western countries.

The decline in mortality after World War II has been significant. The lifespan of men has increased by twelve years and that of women by thirteen. Nevertheless, inequality still exists between men and women, and the difference between their life expectancies has actually grown. Today women live eight years longer than men. This has long-ranging repercussions on many areas of society - one being pension policy. When stated roughly, the Finnish male earns his pension, but never has a chance to use it.

When examining the decline in mortality over ten-year-periods in the last few decades, the 1950s and the 1970s stand out clearly from the other decades. During these two decades mortality declined the most. In the 1980 s the decline in mortality has not been as strong. In the 1970 s the lifespans of men and women increased by over three years. On the other hand, in the 1980 s the increase came to only half of that. This slowing down of the decline in mortality is due mainly to the increase in accidental and violent death among men under 50 years of age. On the other hand, the mortality of older age groups also declined in the 1980s (Statistics Finland 1991).

Mortality differences between socioeconomic groups have increased over the last few decades. At the end of the last decade, the life expectancy of male managers and senior administrative and clerical employees was six years higher than among workers. The corresponding difference among women was three years.

Education also increases inequality. In 1990 the mortality of 35-64-year-old men with a basic level of education was more than double that of men with a higher education. In 1981 this difference was about 60 percent. Among women the differences have been smaller. Differences in mortality between different levels of education have increased over the last ten years (Valkonen et al. 1992). 
When examining the Finnish population structure in different years, the population pyramid continues to show a swelling caused by the large age groups. When the large age classes were still children in the 1950 s, the population structure formed a traditional pyramid. Because of the decline in the birth rate, the population pyramid began to lose its traditional shape and now resembles more of an onion. The swelling caused by the large age groups is now at the level of those over 40 .

On the other hand, though, the growth in the lifespan caused by decreasing mortality has increased the number of old people and, at the peak of the population pyramid, one can clearly distinguish the female majority among the elderly. The population pyramid is "leaning" toward the right.

Today the large age groups seem to be in a key position, when examining the supply and demand for services provided by society. They will continue to be, for a long time, the largest age groups in the population structure, and the swelling in the population pyramid will move upward year by year, at the same time transferring the need for age-specific services to the older age classes.

\section{The future depicted by the population projection}

Current population development provides a basis on which to examine future population development. About every three years, Statistics Finland has compiled a population projection for each municipality, which has been used widely as a basis for various kinds of decisions and plans gauging the future (Statistics Finland 1992b).

This population projection is compiled in the form of two calculations. The first is a trend calculation which takes into consideration the development of the birth rate, mortality and migration. The other is a calculation of the population's self-sufficiency and it only takes the birth rate and mortality into account. In addition, Statistics Finland has compiled annual calculations for the whole country using various assumptions concerning the birth rate, mortality and migration.

In this paper the examination is based on a trend calculation of the population projection for each municipality. This population projection extends to the year 2030. In addition, Statistics Finland has compiled two alternative calculations of population development, one of which anticipates Finland's future migration and the other a rise in the birth rate. In the following is a brief presentation of the assumptions used in the various population projections:

In the trend calculation, it is assumed that, starting in 1995 , fertility will remain at the average level it reached at the end of 1980 s. Thus the total fertility rate would be 1.72. It is anticipated that the small rise in fertility now occurring will be temporary. It is also anticipated that, among men, mortality will decrease by the year 2010, so that their life expectancy will rise from the current 70.9 years to 73.3 years. The life expectancy of women is now 78.9 years and according to the projection it will be 80.2 years in the year 2010. Net migration is assumed to be zero starting in 1994.

In the population renewal calculation, fertility will rise by the year 1995 to renewal level, that is the total fertility rate will be 2.1 . Assumptions concerning mortality and migration are the same as in the trend calculation.

In the migration calculation it is assumed that, starting in 1993, net migration will be $+10,000$ per year. This net migration means that annual immigration figures must be $15,000-20,000$, for one can assume that there will also be people emigrating from Finland. In the 1980 s an average of 8,000 people emigrated from Finland annually. The assumptions concerning the birth rate and mortality are the same as in the trend calculation.

These three calculations provide a good basis for examining how the current popu- 
lation structure will change in the future. It is obvious that many factors will have an impact on future population development and that most of them cannot be regulated from Finland. At the moment one can indicate for certain at least the most essential factors in future population growth. The foremost of these is the quantitative growth of old people, when the large age groups reach retirement age. The prediction of migration is the most uncertain of these phenomena. Finland has not been a country which attracts many immigrants. On the other hand, immigrants have not been needed, because our age structure, mainly due to the large age classes, has been working-ageintensive. Immigrants "patch up" shortages in the population structure. In addition, the employment of women has been noticeably higher than in Central Europe, for example.

The disintegration of the Soviet Union led immediately to a rise in the number of immigrants to Finland - although most of the immigrants were Ingrians, who are return migrants. In addition, conjectures about the impact of the EEA and, later, of the EU on Finnish population development now appear to be merely conjectures.

In all estimates, Finland is usually considered a migrant-recipient country and, at least in the near future, the dismantled Soviet Union appears to be one potential area of departure for immigration to Finland - at least in regard to the number of immigrants. On the other hand, Finland's current employment situation does not attract people from other countries and it has been estimated that the employment situation will continue to be poor for many years to come. Assumptions about the growth of the lifespan are based partly on the fact that the mortality of Finnish males is one of the highest in the industrialized countries. One of the aims of the "Health for All by the Year 2000" - program (Ministry of Social Affairs and Health, 1986), is to implement measures, which can be used especially to decrease premature death among men of working age. In addition, the program contains numerous measures for decreasing total mortality, so that it will correspond to the level of mortality in other countries. Women, on their part, have already reached this goal.

According to the trend calculation, Finland's population in the year 2001 will be $5,096,000$ at its highest. After this the population would begin to decline. In 2030 the population will have dropped to $4,772,000$ persons. According to the population renewal calculation and the migration calculation, the population in 2030 will clearly be higher. The population renewal calculation estimate would raise the population to $5,298,00$ and the migration calculation to $5,239,000$ persons.

Neither of the last-mentioned alternatives guarantees growth of the total population figures, instead, according to the migration calculation, the population will begin to decrease beginning in the year 2020 and three years later according to the population renewal calculation. In the long run, the population renewal calculation would halt the diminishing of the total population.

\section{The number of births will decline}

The trend calculation assumes that the birth rate will stay at the level it reached at the end of the 1980s. As a result of ever smaller age groups reaching childbearing age, increasingly smaller age classes will be born. While there were 66,000 children born in 1991 , in 2030 the number of children being born is predicted to be 47,000 .

If fertility were to increase to renewal level, meaning an average of 2.1 children per woman of childbearing age, the number of children being born would increase slightly at first. According to this calculation, slightly over 70,000 children would be born in the mid-1990s. After that the number of births would drop somewhat, but it would still remain annually above the current level. 
In the long run, a population growth alternative of this kind would halt the decline in the total population and the annual number of births and deaths would be the same - the population would have reached a stable state. Today this alternative seems too far from reality, however.

\section{The working-age population will decrease}

Today the working-age population is at its highest and will still continue to be high for the next two decades. After the year 2010, the working-age population will begin to diminish and this decline will be relatively steep. It is evident, of course, that with the current prevailing situation the birth rate will not provide an answer to increasing the working-age population (Figure 2).

If in the future, a larger work force is needed than that supplied by natural population increase, then the only answer is to fall back on accepting immigrants. This means that the immigrants would be coming to Finland to fill in the gaps left in the population structure - as has happened elsewhere in Europe during the past few decades.

It is hard to estimate the number of immigrants needed in the years to come, because economic and social development depends today on so many factors. Many of these factors may be very unpredictable.

If immigration to Finland were to develop so that the annual net migration would reach 10,000 persons, the working-age population would then grow and compensate in part for the shortage of persons of working-age caused by the large age classes. Nevertheless, this number of immigrants would not be able to keep the working-age

Fig u r e 2: The development of the working-age population in 1950-2030, according to various population projections

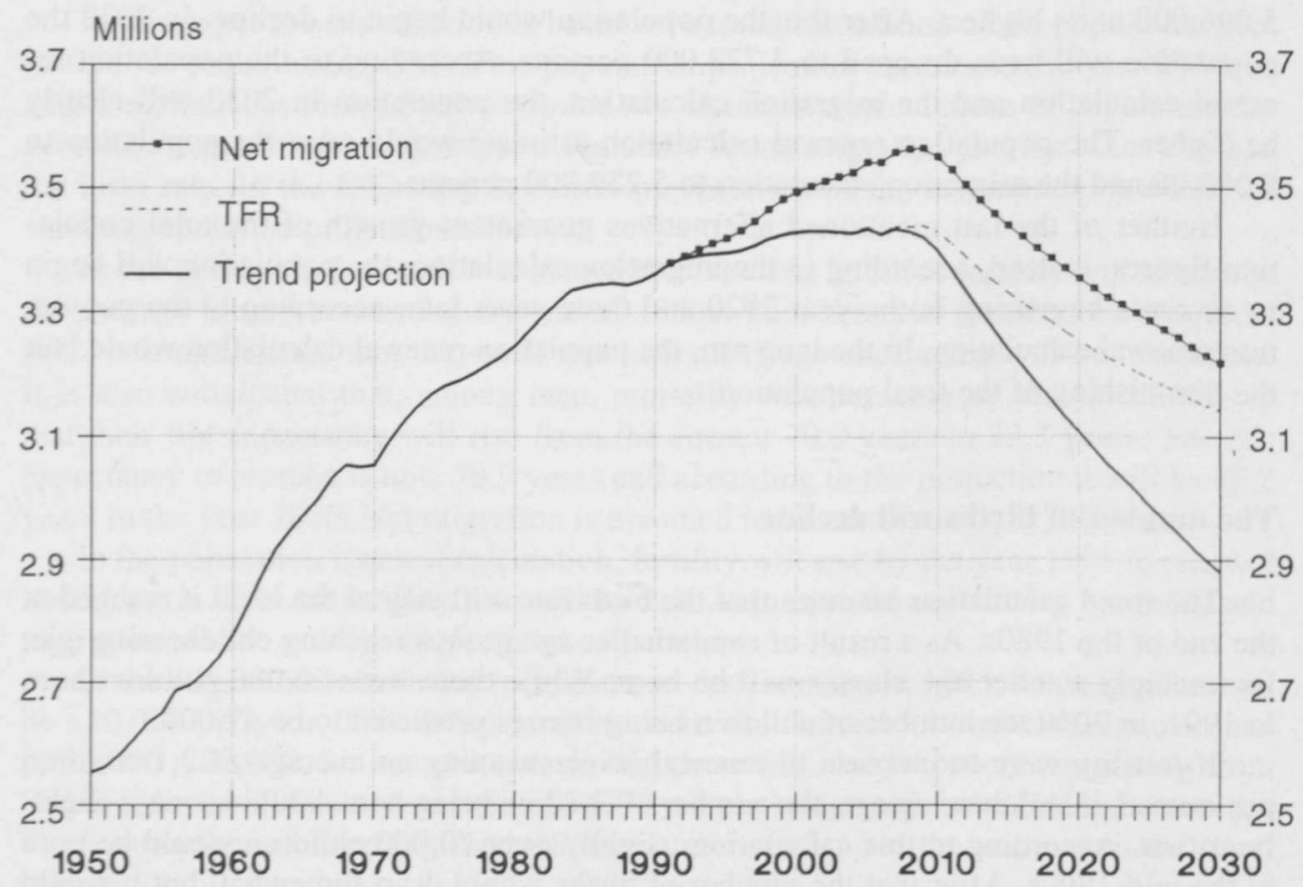

Source: Statistics Finland, population projection. 
population the same size, instead, as the large age classes grew older, the workingage population would begin to decrease.

Keeping the size of the working-age population at the level it is now or slightly lower would require larger numbers of immigrants. This seems unlikely at the moment, at least. In our current employment situation, the labor force supply is secure for many years to come. It is more likely that educating the population will become a problem in the future rather than its size.

\section{A society of old people}

What can be said for certain about the vision of the future provided by the population projection is that the elderly population will grow rapidly after the year 2010 . This growth cannot be affected by raising the birth rate or increasing immigration. These factors will only affect percental shares of the population, if decisive changes occur in them. They will have no impact on the number of elderly people.

The number of old people will increase during the next 40 years by about 470,000 persons and it is estimated that, in the year 2030 , there will be $1,142,818$ persons eligible for old age pensions - almost one person out of four. Growth will be strongest in the oldest age groups. The growth in life expectancy in the trend calculation will triple the number of men over the age of 80 and almost double the number of women. It appears that care for the aged will be facing stiff demands.

The aim of the "Health for All by the Year 2000" -program to increase life expectancy is slightly more optimistic than that held by the compiler of the population projection. If this optimism comes true, it will mean a slight increase in the number of old people. However, we are now already slightly behind the aims set in the mid1980 s by the "Health for All by the Year 2000" -program.

\section{Economic and social development must adjust to decreasing population growth}

For future population development, one noteworthy alternative is to adjust economic and social development to declining population growth. This is not an easy task, for in creating the Nordic welfare state not enough attention was focused on the development of the population's age structure nor on the possibility that some day economic growth may cease.

The age structure of the Finnish population in the years past was most suitable for the social and pension policy reforms made. The swelling in the population structure caused by the large age groups guaranteed that there were people to pay for the benefits. And it is not likely that any political decision maker had the desire to look several decades ahead - we were caught up in the endless circle of population development and economic development.

When examining the development of the population's age structure using the dependency ratio, which shows the portion of children and old people per 100 persons of working age, we find that the dependency ratio has been at its lowest throughout the 1970 s and the 1980s. In the 1950s it was high, mainly because of the large number of children (see also Table 1).

The dependency ratio will clearly change after the year 2010 and will grow higher than the situation prevailing in the 1950s. In addition, among the dependent population, the elderly will compose the definite majority (Figure 3 ).

Not until the year 2030 will there be some relief in the relationship between the different population groups. At that time the impact of the large age groups will begin 
Figure 3: The dependency ratio of the population according to the trend calculation in 1950-2030, children and old people per 100 persons of working age

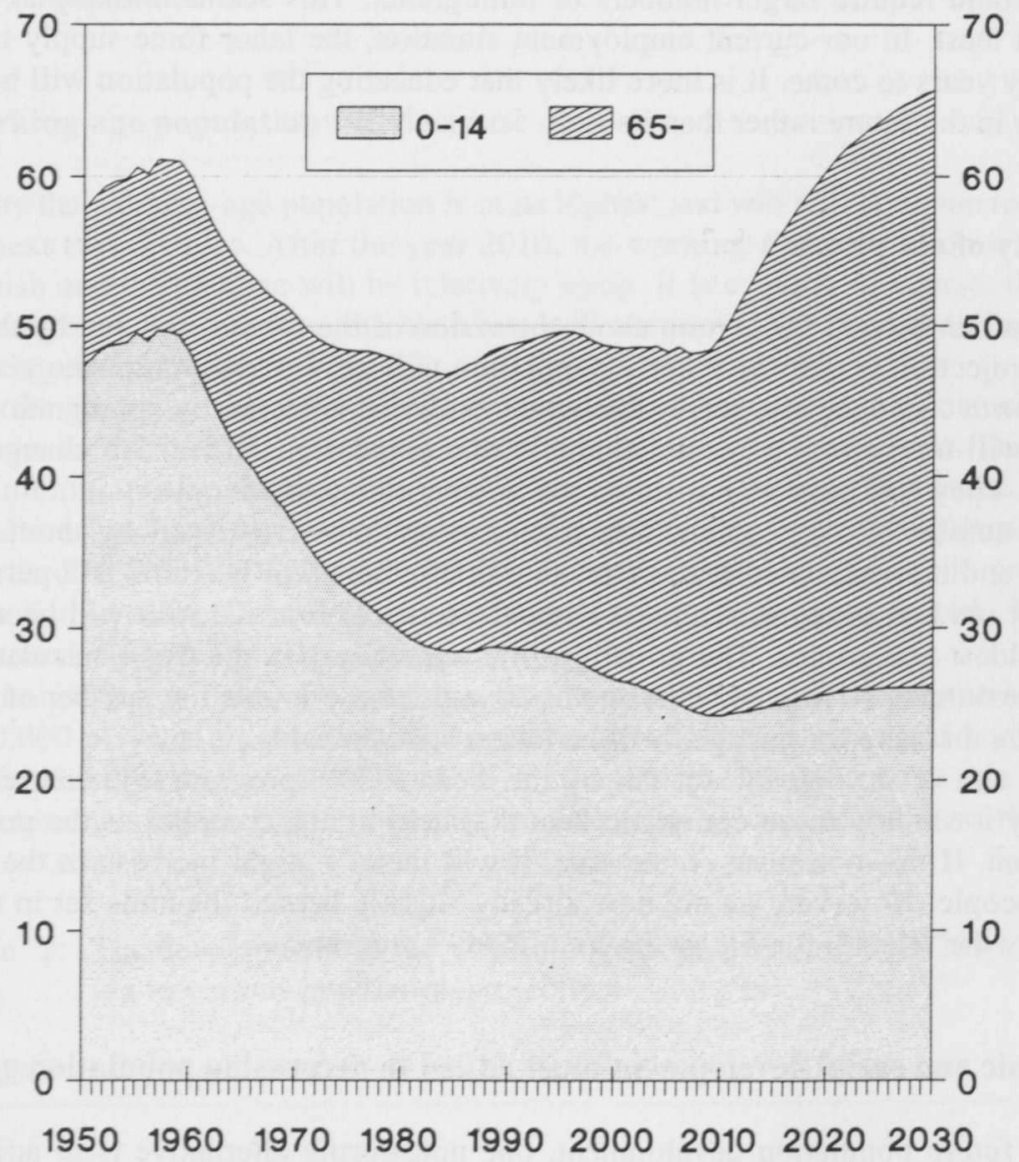

Source: Statistics Finland, population projection.

to disappear. While the dependency ratio today is 49 , according to the trend calculation it will rise to 66 by the year 2030. The migration calculation decreases the dependency ratio to 63 and the renewal calculation, due to a high birth rate, raises the dependency ratio to 69 .

\section{Summary}

Today, the shape of the age structure of the population of Finland is such that future economic and social decisions will demand substantially more consideration than before. The changes in the population's age structure will be so great that we cannot survive with very shortsighted planning.

When talking about population development, attention is often focused only on the growth of total figures. Even now, people often talk merely of increasing the birth rate and letting in immigrants, citing as a reason that the population must not be allowed to decrease. In addition, these both are seen as answers to who will pay the costs of increasing care for the elderly. 
One must remember that population development can be influenced only over a very long span. In the population renewal calculation, the increased birth rate is not visible in the size of the working age population until around the year 2020. Taking in immigrants can be considered a quick solution to the labor force shortage. The migration calculation presented above would appear to provide only temporary relief to the size of the working-age population.

With the unemployed now totaling 450,000 , they form a reserve which in numbers equals many new age groups being born - some are trained and almost all have work experience. It would seem that here, in this part of the population, lies the answer, at least at first, to the future shortage in the working-age population.

\section{References}

Ministry of Social Affairs and Health (1986). Terveyttä kaikille vuoteen 2000. (Health for all by the year 2000). Helsinki.

Nieminen, M. (1992). Suomen väestönkehitys - haaste yhteiskunnalle! (Finland's population development - a challenge for society!). TTT Katsaus 20(4):3-13.

Nikander, T. (1992), Naisen elämänkulku ja perheellistyminen: the woman's life course and the family formation. Population 1992:1. Helsinki: Statistics Finland.

Statistics Finland. (1991). Kuolemansyyt 1990. (Causes of death in 1990). Health 1992:8. Helsinki: Statistics Finland.

Statistics Finland (1992a), Väestörakenne 1991 (Structure of population 1991) Population 1992:11. Helsinki: Statistics Finland.

Statistics Finland (1992b), Väestöennuste kunnittain 1991-2020 (Population projection by municipalities 1991-2020). Population 1992:6. Helsinki: Statistics Finland.

Valkonen, T., Martelin, T., Rimpelä, A., Notkola, V., and Savela, S. (1992). Sosioekonomiset kuolleisuuserot 1981-90 (Socioeconomic differences in mortality in 1981-90). Population 1992:8. Helsinki: Statistics Finland. 